\title{
THE POTENTIAL OF 3D VIRTUAL REALITY (VR) FOR LANGUAGE LEARNING: AN OVERVIEW
}

\author{
Alberto Andujar ${ }^{1}$ and Josef Buchner ${ }^{2}$ \\ ${ }^{1}$ University of Almería, Crta.de Sacramento s/n, Almería, Spain \\ ${ }^{2}$ University of St. Gallen, Müller-Friedbergstraße 34, CH-9400 Rorschach, Switzerland
}

\begin{abstract}
This reflection paper attempts to draw attention to the current situation of 3D Virtual Reality (VR) in the field of language learning. During the last decade, researchers and practitioners have made use of synthetic virtual environments and open virtual spaces to help develop students' language skills. In this sense, computer-generated environments have been used to simulate students' presence within the virtual context. Nevertheless, advancements in technology may lead to change the understanding of virtual environments thanks to the use of 3D VR. Teachers may be able to situate students within the virtual situation, giving them the possibility of experiencing real-life interaction in which target language skills could be developed. Thus, this paper attempts to reflect on the potential as well as possible limitations of this technology for language learning.
\end{abstract}

\section{KEYWORDS}

Virtual Learning Environments, Virtual Reality, Virtual Learning, Language Learning, CALL, MALL

\section{INTRODUCTION}

The rapid growth in the use of digital technology and communication through multimedia devices as well as its growing popularity within the society has led to the exploration of new teaching techniques and materials in educational contexts. The use of digital devices becomes, in many cases, an indispensable element for the transmission, acquisition and exchange of knowledge. Among these technological advances, virtual reality (hereinafter, VR) has become a resource which may offer a great potential as an element for pedagogical purposes. In this vein, Sykes et al. (2008) categorized virtual reality in three types: open virtual spaces such as Second life; multiplayer online games; and synthetic immersive environments. The first two types of virtual reality have been widely investigated, nevertheless the latter is still on the fringes as technology keeps evolving and changes need to be made in order to adapt technological advancements to educational contents and materials. Nevertheless, the potential of immersive virtual environments for language learning and teaching needs to be emphasized as students may have the possibility of engaging in real second language interaction.

The concept of VR was defined as "an interactive database capable of creating a simulation that involves all the senses, generated by a computer, explorable, visual and manipulated in real time in the form of images and digital sounds, giving the sensation of presence in the computer environment "(Levis, 1997: 4). According to this definition, and from the didactic point of view, we can say that the RV could be considered as the didactic resource that would most closely approach the immersion of the student in a real (simulated) context, whether academic, playful or professional. Its potential as a didactic resource has been an element of debate and reflection for more than two decades by educators and teaching professionals (Appel and Mullen, 2000, Biocca, 1997, Bricken, 1990, Helsel, 1992). Numerous studies have addressed the advantages of using VR in the teaching and learning of different subjects, including, among others, a greater commitment and involvement of the student in learning activities, the development of more precise and concrete communicative situations or, when used in group situations, greater cooperation and collaboration among students (Deuchar and Nodder, 2003, Dickey, 2003, Falloon, 2010, Freitas, 2006, Garris, Ahlers and Driskell, 2002, Prensky, 2008, Van den Brekel, 2007). However, VR, as it is conceived today, is far from the use of virtual environments in which the element of greatest importance was the design of the virtual situation or the 
use of virtual worlds (Garrido-Iñigo and Rodríguez-Moreno, 2015). Currently, VR is able to situate the student within the virtual situation (RV 3D), therefore giving him the possibility of experiencing real and authentic situations within the immersive environment. In order to achieve this goal, simple and affordable glasses such as Google Cardboard (2015) and the use of a mobile device are enough to achieve an environment that poses various possibilities from the educational point of view. In this line, Dalgarno and Lee (2010) pointed out that VR could lead to improving the transfer of knowledge and skills to real situations through the contextualization of learning.

Nevertheless, some disadvantages of using this technology has also been found such as the motion sickness generated by the use of virtual reality head-mounted displays. This symptom may occur in some users and, more in particular, in women which were found to be at greater risk (Munafo, Diedrick \& Stoffregen, 2017).

\section{VR AND LANGUAGE LEARNING}

Regarding the teaching and learning of foreign languages, the repertoire in the literature as regards this particular type of immersive VR is more limited. However, there are some recent studies that suggest positive findings of the use of VR for the development of certain skills and competences by the student. It is worth mentioning studies such as Lan (2015) who developed an immersive EFL learning context in order to review in-class materials. The effects of this virtual context used out of the classroom environment were evaluated during one semester. 132 participants were investigated through the use of a 2-iteration action research in which qualitative and quantitative information was collected. Results showed positive outcomes of the virtual environment, particularly with regard to the higher amount of learning opportunities provided to students, the enhancement of participants' EFL performance, and the advantages of a gamified scenario.

Another remarkable study was carried out by Chen (2016), who analyzed the effectiveness of the use of a 3D VR platform in the English classroom in order to foster cognitive and linguistic development of 448 students at a university in Taiwan. The virtual reality environment took place in a department store in which each floor represented a module of the course. This virtual context was mainly focused on vocabulary learning which was evaluated throughout the different modules. Results showed that, apart from learning vocabulary, students improved their phonological, morphological, grammatical and syntactic competence while the use of this resource promoted the development of a more complex and higher-level thinking and reasoning. Moreover, the results of his analysis indicated that the virtual learning environment, only with the characteristics of immersion and ease of use, had a positive impact on students' language cognition. Nevertheless, there is a lack of subsequent studies exploring specifically how this virtual reality environments could exploit language learning skills and which specific aspects may undergo a higher improvement as regards language learning.

Other studies such as Chen (2016) or Lan, Hsiao and Shih (2018) explored 3D VR environments through the use of Second Life to foster language development. In the first case, meaningful real-life tasks were developed and documented throughout the investigation. Findings suggested that 3D VR environments in Second Life facilitated language teaching and learning and optimized learners' experiences. With regard to the second investigation, researchers focused on vocabulary and sentence structure to develop special education students' L1. The information collected through in-class observation, videos and structure interviews indicated that the environment was found to have a positive impact on students' L1 development. More recently, Chiu (2017) explored the effectiveness of a virtual reality environment designed for primary school students in Taiwan. This environment was represented in eight learning scenarios in which students could learn their native language. Findings emphasized an improvement in students' motivation, however a more detailed analysis of the language used may have shed light on specific areas of language development in the platform.

In turn, literature reviews indicated that it is a field with increasing potential as pointed out by relevant scientific journals that address language learning through the use of technology (Lin and Lan, 2015). However, the implementation of 3D VR environments in which students are part of the virtual learning scenario is still very scarce. 


\section{FURTHER RESEARCH LINES AND RECOMMENDATIONS}

Mobile phones manufacturers are gradually incorporating and adapting their devices to improve the immersive experience, which has also contributed to the appearance of VR companies as well as products specifically created for these environments such as remote controls or built-in functionalities within the VR glasses. In this sense, from an educational perspective, practitioners need to stay in touch with the latest advancements that could help exploit learners' characteristics as well as teaching methodologies. Research in the language learning field as regards the use of 3D VR has highlighted positive outcomes from the use of these immersive virtual environments, nevertheless the literature is still scarce, mainly because of the recent developments into this technology, and its potential is yet to be discovered.

The aforementioned studies put into practice the use of 3D VR, which supposes a feeling of greater immersion on the part of the student, who is able to experience in person what is happening around him. These investigations make use of the latest functionalities as regards virtual reality, however the role of the student within the virtual environment is still passive in terms of interaction and communication. For instance, the student is not able to communicate orally with the agents that appear in the virtual situation, therefore, the range of skills to be developed is still limited to those in which the student is the recipient of the information, in this case listening and reading. In this sense, the application of new technologies in the field of language teaching has focused, to a greater extent, on the use of the latest technological advances without prioritizing the implementation of a communicative language teaching approach as suggested by the Common European Framework of Reference for Languages (CEFR). Thus, further studies making use of 3D VR could explore the possibilities for interaction within these environments, contributing to the development of the communicative competence and second language skills in which advances in technology may put into practice the current language teaching methodologies in use.

As it has been observed, despite the benefits reported by the literature regarding the use of VR as a didactic resource, there is still a shortage of studies focusing on the design of this type of tools in the field of foreign language teaching and learning, and an absence of studies carrying out an oral communicative approach through VR. Hence, further research is sought in order to keep pace with the changes in society and technology.

\section{REFERENCES}

Appel, C., and Mullen, T. 2000. Pedagogical considerations for a Web-based tandem language learning environment. Computers and Education, Vol. 34, No. 3-4, pp. 291-308.

Biocca, F. 1997. The cyborg's dilemma: Progressive embodiment in virtual environments. Journal of $\begin{array}{llllll}\text { Computer-Mediated } & \text { Communication, } & \text { Vol. } & 3, & \text { No.2. } & \text { Retrieved }\end{array}$ http://www.ascusc.org/jcmc/vol3/issue2/biocca2.html

Bricken, W. 1990. Virtual reality: Directions of growth. Notes from the SIGGRAPH '90 panel (Technical Report R-90-1). Seattle: Human Interface Technology Laboratory, University of Washington.

Chen, J. C. 2016. The crossroads of English language learners, task-based instruction, and 3D multi-user virtual learning in Second Life. Computers \& Education, Vol. 102, pp. 152-171.

Chen, Y. L. 2016. The Effects of Virtual Reality Learning Environment on Student Cognitive and Linguistic Development. The Asia-Pacific Education Researcher, Vol. 25, No. 4, pp. 637-646.

Chiu, F. Y. 2017. Virtual reality for learning languages based on mobile devices. 16th International Conference on Information Technology Based Higher Education and Training (ITHET), Ohrid, Macedonia, pp. 1-3.

Dalgarno, B. and Lee, M. J. 2010. What are the learning affordances of 3-D virtual environments? British Journal of Educational Technology, Vol. 41, No. 1, pp. 10-32.

Deuchar, S., and Nodder, C. 2003. The impact of avatars and 3D virtual world creation on learning. In S. Mann and A. Williamson (Eds.). Proceedings of the 16th Annual NACCQ. Palmerston North, New Zealand, pp. 255-258. Retrieved from: http://www.naccq.ac.nz/conference04/proceedings_03/pdf/255.pdf

Dickey, M. D. 2003. Teaching in 3D: Pedagogical Affordances and Constraints of 3D Virtual Worlds for Synchronous Distance Learning. Distance Education, Vol. 24, No.1, pp. 105-121.

Falloon, G. 2010. Using avatars and virtual environments in learning: What do they have to offer? British Journal of Educational Technology, Vol. 4, No. 1, pp. 108-122. 
Freitas, S. 2006. Learning in immersive worlds: a review of game-based learning. Bristol. Joint Information Systems Committee. Retrieved from: http://www.jisc. Switzerland ac.uk/eli_outcomes.html.

Garrido-Iñigo, P. and Rodríguez-Moreno, F. 2015. The reality of virtual worlds: Pros and cons of their application to foreign language teaching. Interactive Learning Environments, Vol. 23, No.4, pp. 453-470.

Garris, R., Ahlers, R. and Driskell, J. E. 2002. Games, motivation, and learning: A research and practice model. Simulation y Gaming, Vol. 33, No.4, pp. 441-467.

Helsel, S. 1992. Virtual Reality and Education. Educational Technology, Vol. 32, No. 5, pp. 38-42.

Kukulska-Hulme, A., Lee, H. and Norris, L. 2017. Mobile Learning Revolution: Implications for Language Pedagogy. In Chappelle, C. A. and Sauro, S. (Eds.), The Handbook of Technology and Second Language Teaching and Learning. Willey-Blackwell, Oxford, pp. 217-233.

Levis, D. 1997. Los videojuegos, un fenómeno de masas. Paidós: Barcelona.

Lan, Y. J. 2015. Contextual EFL learning in a 3D virtual environment. Language Learning \& Technology, Vol. 19, No.2, pp. 16-31.

Lan, Y.-J., et al., 2018. Effective Learning Design of Game-Based 3D Virtual Language Learning Environments for Special Education Students. Educational Technology \& Society, Vol 21, No. 3, pp. 213-227.

Lin, T. J. and Lan, Y. J. 2015. Language learning in virtual reality environments: Past, present, and future. Journal of Educational Technology \& Society, Vol. 18, No. 4, pp. 486-497.

Munafo, J., Diedrick, M. and Stoffregen, T. A. 2017. The virtual reality head-mounted display Oculus Rift induces motion sickness and is sexist in its effects. Experimental brain research, Vol. 235, No.3, pp. 889-901.

Prensky, M. 2008. Students as designers and creators of educational computer games: who else? British Journal of Educational Technology, Vol. 39, No. 6, pp. 1004-1019.

Sykes, J.M. 2008. A dynamic approach to social interaction: Synthetic immersive environments \& Spanish pragmatics, Minneapolis, MN: University of Minnesota. (Doctoral dissertation)

Van den Brekel, A. J. P. 2007. Get your consumer health information from an avatar!: health and medical related activities in a virtual environment. European Association for Health Information y Libraries Workshop, pp. 12-15. 